\title{
Psychological Needs and Source Linkages in Undergraduate Information-Seeking Behavior
}

\author{
Kathleen Dunn
}

Psychological motivation for information searching is an important area of research that has received relatively little attention. This study addresses these motivations in an academic environment. Psychological needs causing undergraudates to seek informtion in the context of continuing motivation are identified. In addition, the study identifies categories of sources used to satisfy these information needs and empirically establishes significant relationships between the motivating needs and categories of sources used.

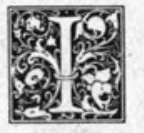

nformation seeking is a behavior, a human activity like writing a memo, driving a car, or talking on the phone. Since it is a behavior, it is logical to propose that it stems from sources common to all behaviors. Psychologists try to determine why people do what they do. Librarians, though intimately involved in information seeking on a professional as well as a personal level, have paid little attention to the psychological sources of this behavior. A look at user studies shows that the focus has been primarily on the demands people make on information systems, secondarily on users and their characteristics, and rarely on the psychological aspects of use. However, as librarianship builds a stronger interdisciplinary base encompassing theory as well as practice, it is appropriate to explore the contribution psychological theories make to our understanding of information seeking behavior.
In 1981 T. D. Wilson, a British colleague, published an article in the Journal of Documentation that challenged me to take a closer look at the psychological motivations for information searching. . In this article he suggests that we shift our emphasis from sources and systems to the user, and that we include in this examination a careful look at the motivational and psychological needs underlying the search for information. Wilson notes that studies dealing with information-seeking behavior often fail to address the core issues. He says, "Such studies may never address the central question of 'information need,' that is, why the user decides to seek information, what purpose he believes it will serve and to what use it is actually put when received. ${ }^{\prime 2}$ To make the point even stronger, Wilson suggests that "it may be advisable to remove the term 'information need' from our professional vocabulary and to speak instead of information seeking towards the satisfaction of needs. ${ }^{\prime 3} \mathrm{I}$

Kathleen Dunn is Head of the Reference Department at California State Polytechnic University, Pomona, California 91768. This paper was presented at the ACRL Fourth National Conference in Baltimore, April 9-12, 1986. 
decided to follow Wilson's advice and study the needs that information seeking might satisfy.

\section{THE STUDY}

Since I am an academic librarian, I chose to investigate the needs influencing undergraduates to seek information. In addition, I wanted to discover the sources they used; and, since students have a wide range to choose from, whether the needs influencing the search also influenced the sources selected.

The study is set within the context of continuing motivation, a term proposed by Martin Maehr, ${ }^{4}$ which is the tendency of students to return to an interest first encountered in class when there is no requirement or external pressure to do so. A basic assumption underlying the study is that undergraduate information-seeking behavior in the context of continuing motivation is an attempt at need satisfaction.

Given the fact that information seeking as need satisfaction is a relatively unexplored area of study within the profession, this work provides answers to a set of questions rather than supporting or rejecting hypotheses. To be precise, the following research questions were investigated: (1) What are the psychological needs that motivate undergraduates to seek course-related information outside of class requirements and discussions? (2) What information sources do undergraduates use to satisfy their information requirements? (3) What significant relationships, if any, can be identified between initiating needs and the sources used to satisfy information requirements?

\section{METHODOLOGY}

The data were collected according to a method frequently used by psychologists in which one explores the parameters of the problem through a series of interviews and then constructs a questionnaire based on the interviews. Each step in the process builds on the knowledge gained from the previous step.

First, I talked to students in their dorms, on the lawns, in the cafeteria, anywhere I could find them (except the library, so as not to prejudice their response to my probing on sources). The critical-incident technique helped them to focus on a particular class and on the particular information they sought. ${ }^{5}$ Through discussion, I attempted to discover why they had persisted in seeking this information. This was the first series of interviews, and from it a group of questions was developed to ask a different set of students.

The second interviews, structured around a list of questions, were asked of a randomly selected sample of students. However, these interviews were still considered exploratory and flexibility was allowed to ask further questions or to change the order of questions to elicit more information.

Third, based on the results of the interviews, I developed a six-page questionnaire. The pretested questionnaire was administered to a stratified, random sample of 625 undergraduates on the La Sierra Campus of Loma Linda University. (Study results are actually based on 566 responses because 59 or 9 percent of the 625 questionnaires collected proved unusable.)

The questionnaire was constructed around three components: (1) sixty-one operational needs (derived from the interviews) and their intensity; (2) sixteen used sources (derived from the interviews) and their importance; (3) demographic data. In the first questions I again used the critical-incident technique to focus the respondent's attention on a particular class in which he or she went beyond class requirements in seeking information. Questions dealing with needs and sources were formulated in terms of a Likert-type scale in which the subjects were asked to rate themselves along a continuum of intensity. This provided enough variability in the data to determine the hidden or submerged factors and offered a better estimate of the actual correlation between the items.

Factor analysis and canonical correlation analysis were used to analyze the data. Factor analysis is a powerful statistical tool for reducing large amounts of data to manageable and understandable proportions. Canonical correlation analysis maximizes the relationship between two sets of 
variables and was used to analyze relationships between the previously identified need and source factors.

\section{NEED FACTORS INFLUENCING THE INFORMATION SEARCH}

The first research question concerned discovery of the psychological needs motivating undergraduates to seek courserelated information beyond all class re- quirements. Responses to the sixty-one need variables were entered into a principle components factor analysis with varimax rotation. Six need factors emerged (table 1): need for other-approval, need for success in chosen profession, need for self-extension, need for self-approval, need for intellectual stimulation, and needs related to a successful college experience. As shown in table 1 , factors are

TABLE 1

SUMMARY OF SIX NEED FACTORS

Factor $\quad$ Variables

1. Need for

Other-Approval

2. Need for Success in Chosen Profession

3. Need for Self-Extension

4. Need for Self-Approval

5. Need for Intellectual Stimulation

6. Needs Related to a Successful College Experience
Need to have classmates think I'm smart

Loadings

Need to compete with classmates for teacher's approval

Need to do more than is required for the class so that I can feel equal to my classmates

Need to have friends think I'm smart

Need to have teacher notice me

Need to prove myself to my husband/wife or boyfriend/girlfriend

Need to be well prepared for chosen profession

Need to be successful in chosen profession

Need to have broader understanding of the subjects that relate to my chosen profession

Desire for more information about my major

Need to meet requirements for employment in my chosen profession

Need to know wide variety of things so I can feel secure in terms of job market

Desire to compete better in job market

Need to learn more about God

Need to know more so that when I have children I can do a better job of raising them

Desire to have a broader outlook toward life and people

Need to know more in order to help others

Need to become a whole person in terms of the mental, physical, and spiritual

Need to understand different people and their environments

Desire to know and understand in order to feel better about myself

Need to avoid feeling frustrated by lack of knowledge

Need to live up to my expectations of myself

Need to feel intelligent

A feeling of insecurity when I think I should know something but I don't

Enjoyment of learning for its own sake

Personal interest in subject of class

Inner drive to learn more about the subjects that make me curious

Need for the excitement and fun of finding answers

Personal satisfaction

Need to get my money's worth out of college

Need to get good grades

Need to feel that my parent's money is well spent on my college education

Need to get everything I can out of my college education

Need to know in order to do better in upcoming classes

Need to understand basic content of course 
named according to the variables that load highest on them, in this case, the need variables.

Examination of these need factors shows that they are at one level quite specific to the educational environment; they arise from the people, situations, and expectations that are part of an undergraduate educational setting. Within the limits of the study, it can be said that undergraduates decide to pursue an interest in a problem encountered in class because they seek approval, knowledge, success, and mental and spiritual challenge. These needs are stimulated by the expectation and cultural milieu of the college/university setting and are generally satisfied by the people, situations, and opportunities inherent within it. On another level, the need factors are examples of the more general and basic needs proposed by Abraham Maslow and refined by C. P. Alderfer. ${ }^{6,7.8}$ Alderfer's E.R.G. theory proposes three basic categories of needs-existence, relatedness, and growth. His theory states that these needs are innate and that they energize and sustain behavior through cycles of desire, satisfaction, and frustration. Existence needs include all material and physiological desires. Relatedness needs center around relationships. Growth needs impel people toward challenge, creativity, and the full expression of their potential.

Existence needs, evident in need factor 2 and need factor 6 , emerge as strong needs to know enough to compete in the job market and to be successful in a profession. These are the expected outcomes of a college experience and they help ensure the individual's adequate supply of material resources that will satisfy the need for a physically secure environment. Relatedness needs, that is needs for approval, acceptance, belonging, and love are most evident in need factors 1 and 3. Growth needs, those concerned with competence, mastery, self-transcendence, and selfactualization, are evident in need factors 2, 3, 4, and 5. Relatedness and growth needs predominate in the undergraduates surveyed. This is consistent with Maslow's and Alderfer's views that existence needs are generally satisfied in our culture and that people tend to experience greater needs for love, belonging, approval, and personal growth.

\section{SOURCES}

The second question asked for the sources undergraduates use to satisfy their desire for information. Responses to the sixteen source variables were intercorrelated and the resulting matrix factored by principal-components analysis and submitted to varimax rotation. Five source factors emerged (see table 2): family, friends, libraries, expert, and personal materials.

Many studies make a distinction be-

TABLE 2

SUMMARY OF FIVE SOURCE FACTORS

\begin{tabular}{llc}
\hline Factor & Variables & $\begin{array}{c}\text { Factor } \\
\text { Loadings }\end{array}$ \\
\hline 1. Family & Friend's library & .53 \\
& Husband/wife & .51 \\
& Boyfriend/girlfriend & .50 \\
2. Friends & Brother/sister & .49 \\
& Personal library & .40 \\
& Friend & .73 \\
3. Libraries & Classmate & .69 \\
& Casual acquaintance & .40 \\
& Boyfriend/girlfriend & .32 \\
4. Expert & Public library & .57 \\
5. Personal Materials & Departmental library & .53 \\
& College/university library & .48 \\
& Special purpose library & .43 \\
& Teacher's library & .38 \\
& Teacher & .74 \\
& Expert in field & .43 \\
\hline
\end{tabular}


tween formal and informal sources of information and have noted the frequency with which informal, interpersonal sources are used. For the purposes of this study, formal information channels include all printed materials, audiovisual materials, and even formally organized information sessions at conferences and workshops. Informal sources of information are available on an interpersonal basis, center around people, and include conversations, correspondence, etc. Study results suggest that undergraduates make considerable use of informal, interpersonal sources. Three of the five source factors are composed primarily of informal sources-source factors 1, 2, and 4. This is consistent with studies of other groups. ${ }^{9,10,11}$ However, in an analysis of the sixteen sources for their importance in providing information, library ranked second and personal library ranked fourth (see table 3). Teacher ranked first. This pattern supports that implied in Andrew Hardy's study of speed and content as factors in the choice of an information source. ${ }^{12}$ Authoritative, informal sources are often chosen first, followed by authoritative, formal sources.

\section{NEED-SOURCE RELATIONSHIPS}

The third research question was resolved by submitting the six need factors and five source factors to canonical correlation analysis in order to determine what relationships, if any, existed between them. Three significant canonical variates emerged from this analysis (see table 4) that show there are indeed statistically significant relationships between certain need and source factors. The first canonical variate indicates that individuals with needs for other approval and selfextension tend to use friends and family as information sources. The thrust of these relationships seems to be that certain needs require people as their primary source of satisfaction and that information seeking, as well as other activities, can be used as a means to this end. The second canonical variate shows that those with needs for intellectual stimulation and professional success tend to use libraries and experts as information sources. The implication in this need-source relationship suggests that needs based on the acquisition of knowledge and use of intellectual skills predispose undergraduates to the use of libraries and experts-sources that offer the best resources for the satisfaction of these needs. The third canonical variate, though significant, accounts for a smaller share of the relationship in the data than the first two canonical variates and therefore is more difficult to interpret. Basically, this variate suggests that subjects with strong other-centered needs use family as sources of information more frequently than libraries or friends; and that subjects with a strong need to be successful in college tend to seek friends and libraries as information sources rather than family.

TABLE 3

IMPORTANCE OF INFORMATION SOURCES: MEANS AND RANK ORDER

\begin{tabular}{llc}
\hline \hline Source & Mean & Rank \\
\hline Teachers & 1.92 & 1 \\
College/university libraries & 2.18 & 2 \\
Expert in field & 2.35 & 4 \\
Personal library & 2.64 & 3 \\
Friend & 2.78 & 5 \\
Classmate & 3.00 & 6 \\
Public library & 3.13 & 7 \\
Bookstore & 3.15 & 8 \\
Departmental library & 3.23 & 9 \\
Casual acquaintance & 3.41 & 10 \\
Brother/sister & 3.48 & 11 \\
Special purpose library & 3.52 & 12 \\
Teacher's library & 3.56 & 13 \\
Boyfriend/girlfriend & 3.57 & 14 \\
Friend's library & 3.67 & 15 \\
Husband/wife & 3.80 & 16 \\
\hline
\end{tabular}

Note: The scale runs from 1 to 4 . Small numbers indicate greater importance. 
TABLE 4

SUMMARY OF CANONICAL VARIATES

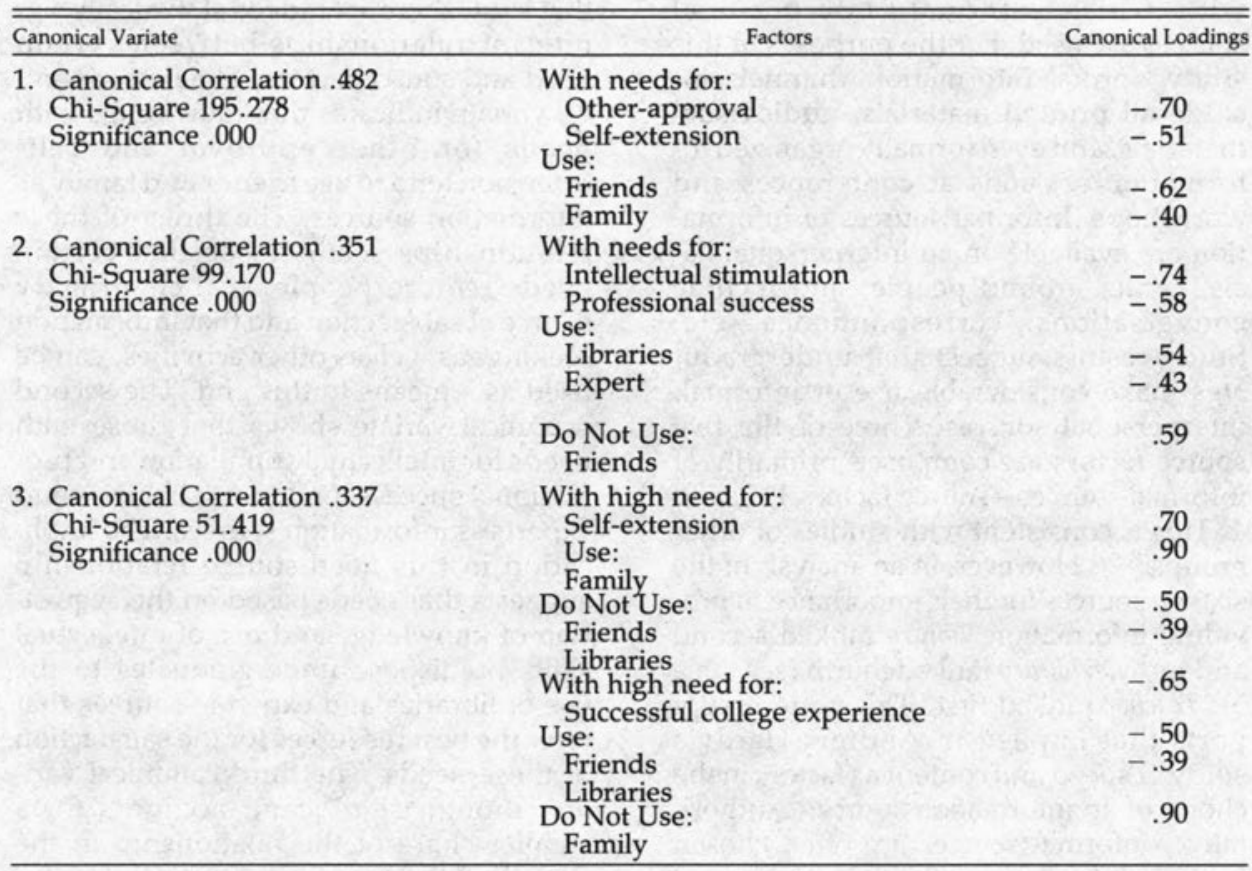

\section{IMPLICATIONS}

Others have included psychological factors in information studies; ${ }^{13,14,15}$ however, this research is unique in two respects. It identifies a group of needs motivating information searching in a particular class of people and it finds statistically significant relationships connecting these needs to categories of sources. ${ }^{10}$ As a result, we now have empirical evidence to assist us in better understanding the motivational factors behind a student's search for information in an academic environment.

The need factors identified help us to understand the psychological context in which students pursue their studies. That some of these needs influence choice of information sources is not surprising, since our needs exert influence over much of our behavior. Neither is it surprising that many students do not use the library. A variety of sources is available to them. The library is only one of these, and, for rea- sons that are now clearer, it is often not their first choice.

These need-source relationships suggest that we should continue our efforts to make the library user friendly. Bibliographic instruction, reference service (along with friendly smiles and a supportive attitude), suggestion boxes, etc., really do help establish our friendship with students as well as our competence as professional information providers. But perhaps this is not enough.

Librarians do not have the same level of exposure to students as teaching faculty nor do they participate as frequently in student activities outside the library. As a result of their broader exposure to students, teachers often develop lasting friendships with them. (It is interesting to note that in this study, teachers were considered the most important source of information.) Might it not be possible for us to participate more frequently with students in campus activities. Several things 
come to mind-join student clubs in which you have an interest, sponsor a college bowl, start a student reading group, develop a student-library liaison program.

Much more research needs to be done in this area. The results of this study can become hypotheses for future research to be conducted in a similar environment or modified for an entirely different context. Until we have more data on need-source linkages, it will be difficult to design systems that take these relationships into account. But the possibilities are exciting because libraries provide a variety of types of sources, both formal and informal.

\section{REFERENCES}

1. Thomas D. Wilson, "On User Studies and Information Needs," Journal of Documentation 37:3-15 (Mar. 1981).

2. Wilson, "User Studies and Information Needs," p.7.

3. Wilson, "User Studies and Information Needs," p.8.

4. Martin L. Maehr, "Continuing Motivation: An Analysis of a Seldom Considered Education Outcome," Review of Educational Research 46:443-62 (Sept. 1976).

5. J. C. Flanagan, "The Critical Incident Technique," Psychological Bulletin 51:327-58 (July 1954).

6. Abraham Maslow, Motivation and Personality (New York: Harper, 1954).

7. Abraham Maslow, The Farther Reaches of Human Nature (New York: Viking, 1971).

8. C. P. Alderfer, Existence, Relatedness, and Growth: Human Needs in Organizational Settings (New York: Free Pr., 1972).

9. Herbert Menzel, The Flow of Information among Scientists (New York: Columbia Univ., Bureau of Applied Research, 1958).

10. Janet Friedlander, "Clinician Search for Information," Journal of the American Society for Information Science 24:65-69 (Jan./Feb. 1973).

11. H. J. C. Matheson, Information Seeking Behavior and Attitudes to Information among Education Practitioners (Ph.D. diss., Univ. of British Columbia, 1979).

12. Andrew Hardy, "The Selection of Channels when Seeking Information: Cost/Benefit vs. LeastEffort," Information Processing \& Management 18:289-93 (Sept. 1982).

13. E. B. Parker and W. J. Paisley, Patterns of Adult Information Seeking (Stanford, Calif.: Stanford Univ., 1966). (ED 010 294).

14. Douglas Zweizig, Predicting Amount of Library Use: An Empirical Study of the Role of the Public Library in the Life of the Adult Public (Ph.D. diss., Syracuse Univ., 1973).

15. Morell D. Boone, Expectancies and Values as Predictors of Motivation of Pre-Decisional Information Search (Ph.D. diss., Syracuse Univ., 1980).

16. Kathleen K. Dunn, "Psychological Needs and Source Linkages in Undergraduate InformationSeeking Behavior: A Factor Anayltic and Multiple Correlation Study (Ph.D. diss., Univ. of Southern Calif., 1984). 